\title{
Lung cancer screening by low-dose spiral computed tomography
}

\author{
R.J. van Klaveren*, J.D.F. Habbema\#, J.H. Pedersen", H.J. de Koning”, M. Oudkerk ${ }^{+}$, \\ H.C. Hoogsteden*
}

Lung cancer screening by low-dose spiral computed tomography. R.J. van Klaveren, J.D.F. Habbema, J.H. Pedersen, H.J. de Koning, M. Oudkerk, H.C. Hoogsteden. (C) ERS Journals Ltd 2001.

ABSTRACT: The poor prognosis of lung cancer has barely changed in the last decades, but the prognosis is better when the disease is detected earlier. Lung cancer screening by chest radiography did not lead to a decrease in lung cancer mortality, presumably because the chest radiograph is a poor screening tool with low sensitivity.

With the advent of the low-dose spiral computed tomography (CT) scan it has become feasible to detect early invasive stage $I$ lung cancer in $80-90 \%$ of cases. This technique could possibly decrease lung cancer mortality, but the extent of this effect is as yet unknown, and whether lung cancer screening will be cost-effective is yet to be determined. These questions can only be resolved in a randomized controlled trial with lung cancer mortality as an unbiased end-point.

In this review, the initiatives to evaluate low dose spiral CT screening for lung cancer in Japan, USA and Europe are presented. In the USA and Japan, evaluation is in onearmed studies, whereas in many European countries randomized trials are now being planned and several one-armed studies have been initiated. A formal collaboration among these countries has now been set up.

It is strongly recommended that lung cancer screening be evaluated in randomized trials in order to allow evidence-based health policy decisions to be made on this subject. Eur Respir J 2001; 18: 857-866.

\begin{abstract}
*Dept of Pulmonology, University Hospital Rotterdam, Rotterdam, the Netherlands. ${ }^{\#}$ Dept of Public Health, Erasmus University Rotterdam, Rotterdam, the Netherlands. "Dept of Cardiothoracic Surgery, Gentofte Hospital, University of Copenhagen, Copenhagen, Denmark. ${ }^{+}$Dept of Radiology, University Hospital Groningen, the Netherlands.
\end{abstract}

Correspondence: R. van Klaveren, Dept of Pulmonology, University Hospital Rotterdam, Dr. Molewaterplein 40, 3015 GD Rotterdam, The Netherlands. Fax: 31104634856

Keywords: Early detection

lung cancer

randomized trial

screening

secondary prevention

spiral computed tomography

Received: August 302000

Accepted after revision April 302001
Lung cancer is the most common cancer in terms of both incidence (1.04 million new cases per year; $12.8 \%$ of the world total) and mortality (921,000 deaths; $17.8 \%$ of the world total) [1]. Incidence and mortality are increasing rapidly, especially in southern and eastern European countries [1]. Lung cancer remains a lethal disease. The survival rate after 5 yrs as measured by the Surveillance, Epidemiology and End Results programme in the USA is $14 \%$, the best recorded at a population level. The average 5-yr survival rate in Europe is $8 \%$, although differences exist between countries [1]. Presently, $78 \%$ of patients with lung cancer have locally-advanced or metastatic disease (stages III/IV) at diagnosis, while only $22 \%$ present with a possibly curable disease (stages I/II). Currently, the average 5-yr survival rate of early stage lung cancer (I/II) is $40-80 \%(70-80 \%$ for stage $\mathrm{I})$, for more advanced disease (stages III/IV) the 5-yr survival rate is strongly dependent on the nodal $(\mathrm{N})$-status (stage III) being $20 \%$ on average, and almost $0 \%$ for metastatic disease (stage IV) [2]. Although the prognosis has improved somewhat between 19601990 , this is mainly due to stage migration and more refined surgical techniques [3]. In contrast, mortality from all forms of cancer (except lung cancer) has declined by $25 \%$ in the period $1950-1998$ in the USA, primarily due to improvements in medical care, including screening, diagnosis and treatment [4]. Also in the UK, mortality from female breast cancer, cancers of the colon, rectum and bladder, and melanoma of the skin decreased in the last $5 \mathrm{yrs}$ [5].

Although there are accepted screening strategies for breast and cervical cancer, and recommendations for colon and prostate cancer in some countries, there is no public health strategy for the early detection of lung cancer [6]. In the USA, 46.3 million individuals smoke, and $\sim 45$ million are former smokers. Former smokers now comprise an increasing percentage of newly diagnosed cases of lung cancer. As half of the new cases of lung cancer occur in exsmokers, the benefits of smoking cessation programmes are limited.

Previous articles in this series: No. 1: Steels E, Paesmans M, Berghmans T, et al. Role of p53 as a prognostic factor for survival in lung cancer: a systematic review of the literature with a meta-analysis. Eur Respir J 2001; 18: 705-719. 
Moreover, in smoking cessation programmes, only $10-20 \%$ succeed in quitting [7]. Therefore, the call for a clear screening policy to stop the lung cancer epidemic is stronger than ever.

\section{Screening for lung cancer in past decades}

From 1951-1975, 10 prospective studies have been performed using chest radiography (CXR) [8-20]. Only four studies had a prospective randomized controlled design (The Memorial-Sloan Kettering Lung Project (MSKLP), The John Hopkins Lung Project (JHLP), The Mayo Lung Project (MLP), and The Czechoslovakian Study (CS)) [15-20]. Of these four studies, the MSKLP and the JHLP investigated the benefit of adding sputum cytology to CXR screening, but it did not determine whether lung cancer screening by CXR per se should be recommended. In fact, only the MLP and the CS addressed this issue [17, 19, 20].

The nihilism with regard to lung cancer screening was based on the negative results of the randomized MLP and CS studies, which failed to demonstrate that screening leads to a reduction in lung cancer mortality. Therefore, the American Cancer Society declared in 1980, "it does not recommend early detection of lung cancer but urges a focus on primary prevention... people with signs or symptoms should consult their physicians" [21]. As a result of this policy, the vast majority of lung cancer patients are symptomatic at diagnosis. In a recent series of 1,568 lung cancer cases in Europe, only $29(1.8 \%)$ were asymptomatic [22], and only $25 \%$ of the new cancer cases present with localized disease [23].

In the last few years, the conclusions of the MLP and CS studies have been critically re-evaluated [25-29]. Lack of statistical power has been noted as a shortcoming of both the MLP and the CS studies. Initially, the MLP had only $48 \%$ power to detect a $20 \%$ reduction in mortality, but by extending the follow-up to $>20 \mathrm{yrs}$, the power of the study has been raised to $88 \%$ [30]. On a questionnaire at the end of the MLP study, $72 \%$ of the control population reported to have had a CXR (contamination), and compliance in the intervention group was $75 \%$. In the CS study, early detected lung cancer cases were often not treated by curative surgery or radiotherapy because of patient refusal or medical contraindications. Because of these problems, a sizeable effect could have been missed [31].

\section{Limitations of chest radiography in the detection of lung cancer}

It is becoming increasingly evident that conventional CXR is a poor screening tool. Early stage lung cancer is rarely detected by CXR because the peripheral adeno- and large cell carcinomas are often ill defined, and the more central squamous cell carcinomas often show rapid growth [32, 33]. Retrospectively, the median delay in the diagnosis of lung cancer was found to be $>1 \mathrm{yr}$ [34]. The miss-rate for lesions $\leqslant 10 \mathrm{~mm}$ was $70 \%$, for those $10-20 \mathrm{~mm}$ it was $30 \%$ and for lesions $21-30 \mathrm{~mm}$ it was $25 \%$. In the series by Sone et al. [35], even $80 \%$ of lung cancers $\leqslant 20 \mathrm{~mm}$ visible on CT were missed by CXR. The overall accuracy of interpretation on CXR for lung cancer (compared with spiral CT) was 61\%, the sensitivity 23\% and the specificity $96 \%$ [35]. Despite the low sensitivity of the CXR, the National Cancer Institute started a randomized lung cancer screening trial with CXRs as part of the Prostate, Lung, Colorectal and Ovarian (PLCO) cancer screening trial in 1993. In this trial, 150,000 males and females of 55-74 yrs were randomized between routine medical care, or screening for lung, colorectal and prostate or ovarian cancer. The lung cancer screening included an annual CXR plus sputum cytology [36-38]. As yet, no results are available from this trial.

\section{The "low-dose" spiral computed tomography: a novel screening technique}

In comparison to the chest radiography, radiograph computed tomography (CT) is not hindered by the superimposition of anatomical structures and has a better contrast resolution. As a result, small lung cancers can be detected with greater accuracy [39-44]. The spiral CT allows rapid acquisition of a large volume of image data so that in one single breath-hold (20 s) the whole lung can be scanned. Lung parenchyma is especially suited for spiral CT scanning with increased pitch because there is an inherent contrast between normal lung tissue and soft tissue-density lesions, so that lesions as small as $3 \mathrm{~mm}$ can be detected [39-44]. Recent advances in technology, including the multi-slice technology, cine-viewing and threedimensional (3D) reconstruction techniques have further improved the ability of spiral CT to detect and accurately characterize lung nodules. By reducing the tube current (mAs value) according to the socalled "low-dose" protocol $(120 \mathrm{kV}, 50 \mathrm{mAs})$, the radiation dose can be reduced to approximately oneeighth of the dose associated with a standard dose CT. A low radiation dosage is of paramount importance when applied to a large number of a priori healthy, asymptomatic individuals. The breast dosage delivered by low-dose spiral CT is 3.6 milliGray (mGy) (comparable with the dosage delivered by two-view mammography), and the effective dosage is $0.65 \mathrm{mSv}$. In comparison, the effective dosage of a two-view CXR is $0.3-0.55 \mathrm{mSv}$, and a conventional CT $3-27 \mathrm{mSv}$ $[45,46]$. A further reduction in radiation dosage is feasible because the optimal tube current for the detection of pulmonary nodules without sacrificing diagnostic accuracy has been found to range 25-40 mAs, dependent on the body habitus $[46,47]$.

\section{Spiral computed tomography: test characteristics}

The sensitivity of a screening test is usually expressed as the ratio between the number of cases detected at screening and this number plus the number of socalled interval carcinomas [48]. Interval carcinomas are cancers, which are detected in the interval between 
two screening rounds after a "negative" result in an earlier round. So far, data on the incidence of interval carcinomas are only available from the Early Lung Cancer Action Project (ELCAP) [44]. In 27 cases detected during the prevalence screening, two interval cases were found in the interval between the prevalence screening and the first annual repeat (incidence) screening, so that the sensitivity was estimated at $93 \%$ (27 out of 29) [49]. In fact, it is possible that some cancers were missed, but then detected at the second screening; whereas, it is possible that some of the interval cancers were not detectable at the earlier screening. Computer modelling of the natural history of the disease, based on clinical data and screening data, may provide better estimates of the sensitivity $[50,51]$.

The relative sensitivity of the test can be estimated by using the ratio between $\mathrm{CT}$-detected cases and the number of cases detected by CT, plus any other technique such as sputum cytology. The reference is the total number of lung cancer cases detected, regardless of the method used. In studies using screening by both CT and sputum cytology, 7\% of all screen-detected lung cancer cases were detected only by sputum cytology. By using this estimation, the sensitivity of the spiral CT is $93 \%$ (95\% confidence interval (CI) $83-99 \%$ ) $[40,43,52]$. Compared to the CXR, the CT is 4-10 times as sensitive to detect lung cancer, and therefore, the disease is detected at an earlier stage $[43,44]$. Sone et al. [53] reported on the sensitivity of the CT reading, which increased from $55 \%$ in the first year to $83 \%$ in the second year, probably due to the effect of a learning curve and the introduction of an automated interpretation system for CT images [54].

The specificity of the CT screening studies varied between $79 \%$ in the ELCAP study to $95 \%$ in the study by Sone et al. $[43,44,55]$. These rather low figures are due to the fact that during the first screening trials, single-slice spiral CTs had been used with a slice thickness of $10 \mathrm{~mm}$. All test-positive screenees $(25-50 \%)$ had to undergo a diagnostic standard-dose repeat CT, with high resolution images ( $1 \mathrm{~mm}$ slices) identifying those in whom additional diagnostic work-up was required. With the advent of the multi-slice spiral CT technology, it has become feasible to scan the lung immediately at low dose and high resolution. For routine readings, the $1 \mathrm{~mm}$ acquisitions are fused into $5 \mathrm{~mm}$ slices. However, owing to the thin-slice acquisition, targeted $1 \mathrm{~mm}$ reconstructions can be performed to detect localized calcifications or fat in the nodules. As a consequence, diagnostic standard dose repeat CTs have become redundant and the specificity of the test has increased, with only $0.1-0.4 \%$ false-positive test results $[44,52,56]$, a sensitivity of $\sim 90 \%$, and a specificity of $>99.5 \%$.

\section{Results from current spiral computed tomography screening trials}

Based on the ELCAP design $>20,000$ high-risk smokers and exsmokers have already been included in noncomparative studies (table 1). The general trend is to perform an annual screening, although definitive information about the optimal screening interval is lacking. Henschke et al. [44] screened 1,000 male and female smokers $>60$ yrs of age ( $>20$ pack-yrs). They found $23 \%$ noncalcified nodules (NCN) by spiral CT compared to $7 \%$ by CXR. Malignant disease was detected in $2.7 \%$ by spiral CT versus $0.7 \%$ by CXR. Biopsies were done on 28 of the 233 participants with NCN; 27 had malignant disease and one had a benign nodule $(0.4 \%$ false-positive rate). No one had a thoracotomy for a benign nodule. Stage I lung cancer was

Table 1. - Summary of current low-dose computed tomography screening programmes for lung cancer

\begin{tabular}{|c|c|c|c|c|c|c|c|}
\hline & \multicolumn{7}{|c|}{ Institution } \\
\hline & $\begin{array}{c}\text { Cornell } \\
\text { University, } \\
\text { USA }\end{array}$ & $\begin{array}{c}\text { Hadassah } \\
\text { University, } \\
\text { Israel }\end{array}$ & $\begin{array}{l}\text { Mayo } \\
\text { Clinic, } \\
\text { USA }\end{array}$ & $\begin{array}{c}\text { Moffitt } \\
\text { Cancer } \\
\text { Center, USA }\end{array}$ & $\begin{array}{c}\text { Muenster } \\
\text { University, } \\
\text { Germany }\end{array}$ & $\begin{array}{c}\text { National } \\
\text { Cancer } \\
\text { Center Hospital, } \\
\text { Japan }\end{array}$ & $\begin{array}{c}\text { Shinshu } \\
\text { University, } \\
\text { Japan }\end{array}$ \\
\hline \multicolumn{8}{|l|}{ Inclusion Criteria } \\
\hline Age yrs & $\geqslant 60$ & $\geqslant 50$ & $\geqslant 50$ & $\geqslant 45$ & $\geqslant 40$ & $\geqslant 50$ & $>40$ \\
\hline Smoking history pack-yrs & $\geqslant 10$ & $\geqslant 10$ & $\geqslant 20$ & $\geqslant 30$ & $\geqslant 20$ & No & $\geqslant 0$ \\
\hline Fit to undergo thoracic surgery & Yes & No & Yes & Yes & No & No & No \\
\hline History of malignancy allowed & No & No & No & No & No & Yes & Yes \\
\hline \multicolumn{8}{|l|}{ Protocol design } \\
\hline Screening frequency & Annual & Annual & Annual & Annual & Annual & Biannual & Annual \\
\hline Patients at entry & 1000 & 300 & 1520 & 1150 & 1000 & Ongoing & 7847 \\
\hline Total duration yrs & Ongoing & 3 & 4 & 4 & 4 & Ongoing & 3 \\
\hline \multicolumn{8}{|l|}{ Baseline screen } \\
\hline Number of persons screened & 1000 & 619 & 1520 & 493 & 919 & 1707 & 7847 \\
\hline Number of cancers detected & 27 & 4 & 19 & 11 & 17 & 13 & 40 \\
\hline Stage I \% total detected & 81 & 100 & 65 & 18 & 76 & 77 & 83 \\
\hline \multicolumn{8}{|l|}{ Annual repeat screening } \\
\hline Number of persons screened & 1184 & 50 & 1000 & 91 & ? & 9100 & 10045 \\
\hline Number of cancers detected & 7 & 0 & 2 & 0 & 2 & 21 & 40 \\
\hline Number of interval cancers & 2 & 0 & 0 & 0 & 0 & 0 & 0 \\
\hline Stage I \% total detected & 85 & 0 & ? & 0 & 100 & 81 & 88 \\
\hline
\end{tabular}


found in $81 \%$. For the 1,184 annual repeat screenings, the test was positive in $30(3 \%)$ (table 1$)$. Two subjects died of unrelated causes, in 12 of the subjects the nodules resolved after antibiotics, and growth was documented by repeat CT in eight. They were all biopsied and malignancy was diagnosed in seven of them. In another two subjects lung cancer was detected between the two screening rounds (interval cancers) [49]. DIEDERICH et al. [55] screened 919 male and female smokers ( $>20$ pack-yrs) $>40$ yrs of age in Germany. In this population, $31 \mathrm{NCN}$ were detected. In 15 cases, no biopsy was performed (13 benign appearances on CT, two refusals), and in 16 biopsy was done. In 13 cases, lung cancer was detected, and in three cases, a benign nodule was found $(0.3 \%$ falsepositive rate). The prevalence detection rate was $1.2 \%$ for the whole screened population, $2.0 \%$ in those $>50$ yrs of age and $3.6 \%>60$ yrs of age. Stage I lung cancer was found in $68 \%$ of cancers. In the Mayo Clinic 1,520 smokers $>50$ yrs of age ( $>20$ pack-yrs) have been screened, with a prevalence rate of $0.8 \%$ and a false-positive rate of $0.1 \%$ [52]. These data indicate that the results are reproducible and comparable between the USA and Europe.

Since 1935, radiographical mass screening for pulmonary tuberculosis has been performed in Japan, but since the 1950s, screening has focused on lung cancer. While the efficacy of mass screening for lung cancer was being disputed in the USA and Europe, more than 500,000 people in about $80 \%$ of the local communities in Japan were screened every year, supported by the prefectural agencies and the Ministry of Health and Welfare. In the period 1975-1993 screening has been performed by annual CXR plus sputum cytology, but since 1993, when lung cancer became the leading cause of cancer death in Japan, CT screening has been added to CXR screening. The 5-yr survival rate of lung cancer increased in Japanese studies from $48 \%$ in the period $1975-1993$ in which people were screened by CXR only, to $82.6 \%$ in the period 1993 1998 after the introduction of CT [57]. Currently, 14 spiral CT screening programmes are running in Japan as part of a public health programme, but without the intention to conduct randomized clinical trials (for results of the National Cancer Center Hospital and Shinshu University see table 1).

KANEKO et al. [40] reported an overall lung cancer detection rate of $0.43 \%(93 \%$ stage I) in CT examinations conducted on males $>40$ yrs old who were heavy smokers ( $>20$ pack-yrs). In the mass screening for lung cancer at Shinshu University, Japan, 5,483 people between 40-74 yrs have been screened by spiral CT
[43]. Only one-quarter of them were smokers $(>30$ pack-yrs). The lung cancer detection rate was $0.41 \%$ $(83 \%$ stage I). The lower prevalence rates in Japan than in the USA can be explained by the fact that the underlying incidence rate in Japan is approximately half the incidence rate of the USA, the majority of the people included were nonsmoking and the lower age limit of inclusion was $40 \mathrm{yrs}$. Moreover, people had already participated in a mass screening by CXR and sputum cytology conducted in the same area, so that the reported detection rates do not represent real prevalence data. However, the rate of malignancies detected among CT detected nodules was similar in Japan $(10 \%)$ as in the ELCAP $(12 \%)$ [40, 43, 44].

\section{Evaluation of spiral computed tomography-detected nodules}

Spiral CT detected nodules with benign calcifications (central, popcorn or laminar), nodules with smooth edges and a size $<20 \mathrm{~mm}$ are classified as benign. Lesions $>2 \mathrm{~cm}$, with spiculae, irregular shape, poorly defined edges and eccentric or crescent calcifications are considered malignant. Otherwise they are classified as indeterminate. Indeterminate nodules are solid, smooth-edged and do not show "benign calcifications", air-bronchograms, or converging vessels. They are not spiculated, and are of unknown chronicity. For these noncalcified indeterminate nodules the work-up is dependent on the size of the nodules (table 2) $[44,58]$. Nodules $>10 \mathrm{~mm}$ are malignant in $30-80 \%$ of screening cases, and immediate diagnostic investigation should be initiated $[44,58]$. There is no general consensus for lesions $<10 \mathrm{~mm}$, although many trials follow the ELCAP approach with serial repeat CT to detect growth on $3 \mathrm{D}$ composite images. If growth is detected, it is probable that the nodule is malignant and that the number of false-positive biopsies is very low $[44,52,56]$. Preliminary experience suggests that, with the current technology, a single repeat CT obtained 14-30 days after the first scan can already depict growth in most malignant tumours (doubling times 100-600 days) as small as $5 \mathrm{~mm}$, with a repeat accuracy coefficient of variation of $1-3 \%[59,60]$. The evaluation of newly diagnosed nodules during the annual repeat (incidence) screenings is similar as for the first prevalence screen and largely dependent on the size of the nodules (table 2). During the annual repeat screening, a large number (12 out of 30) of the newly diagnosed nodules resolved after broad spectrum antibiotics, and although not

Table 2. - Management of indeterminate noncalcified pulmonary nodules according to the Early Lung Cancer Action Project (ELCAP)

\begin{tabular}{|c|c|c|}
\hline Nodule size $\mathrm{mm}$ & Probability of cancer $\%$ & Management \\
\hline$<5$ & 1 & HRCT at 3 and/or 6, 12, 24 months \\
\hline $5-10$ & $25-30$ & $\begin{array}{l}\text { Consider biopsy/removal of nodules that increase in size } \\
\text { HRCT at } 3,6,12,24 \text { months }\end{array}$ \\
\hline$>10$ & $30-80$ & Consider biopsy of all of these nodules \\
\hline
\end{tabular}

HRCT: high-resolution computed tomography. 
included in the original ELCAP design, treatment with antibiotics might be considered prior to the repeat CT (3 months later) to document growth [49].

\section{Biases in lung cancer screening}

By using doubling times and 5-yr survival rates for resected and nonresected carcinomas, the lead time (the period of time by which the time of diagnosis has moved forward) can be estimated. The lead time was estimated to be 6 yrs for adeno- and large cell carcinomas, and 1 yr for squamous cell carcinomas, based on the results of CXR screening [61]. CT screening might even further increase the lead time. Length biased sampling refers to apparent improvement in survival due to detection of biologically indolent and slow-growing tumours. The contribution of length bias in lung cancer screening by CXR is suggested to be limited [61], but for CT screening, no data are available.

The issue of overdiagnosis bias in lung cancer screening is yet unresolved [62]. Overdiagnosis is often defined differently by different authors. The most strict and important definition is the additional number of lung cancers being detected that would otherwise never have surfaced clinically, since the person would have died from other causes. Arguments against overdiagnosis are: 1) there is no evidence that latent lung cancer is frequently found at autopsy [63, 64]; 2) data from seven studies show that untreated patients with stage I early-detected lung cancer do not have a protracted and undisturbed survival. Their 5-yr survival is only $0-10 \%$, while stage I surgically treated patients survive in $70-85 \%$ of cases after 5 yrs $[61,65,66]$; and $3)$ there is no biological evidence to support the contention that lung cancer sometimes behaves in a benign fashion. However, McFarlane et al. [67] reported in their epidemiological necropsy study that they had identified a large "reservoir" of undiagnosed lung cancer cases that had neither caused nor contributed to the death of their patients. Overdiagnosis has been proposed as the most likely explanation for the observed incidence difference between the screen and the control arm in the MLP study [26, 30], although it might have been a combination of multiple factors. The cumulative lung cancer incidence has been followed after screening cessation for only 3 yrs on average, which is shorter than the estimated lead time in the MLP study (4-8 yrs) [68]. A longer followup might have offset the observed difference in lung cancer incidence, and other factors, such as allocation failure and underdiagnosis in the usual-care arm, might also have contributed [69]. The risk of overdiagnosis is higher when a tumour is detected in a very early stage. In a recent study of small $(<3 \mathrm{~cm})$ surgically resected peripheral adenocarcinomas that have been followed by CT, tumour volume doubling times ranged from 42 days to 1,486 days, and half of the tumours had doubling times $>1$ yr [70]. With a doubling time of $1 \mathrm{yr}$, it would take the tumour nearly $8 \mathrm{yrs}$ to increase from $5 \mathrm{~mm}$ to $3 \mathrm{~cm}$, in which time the screenee may have died from other causes. Some of the nodules may contain precancerous lesions such as atypical adenomatous hyperplasia (AAH), and $\mathrm{AAH}$ associated with adenocarcinoma might be associated with a more favorable prognosis [71]. Bronchoalveolar carcinoma (BAC) may not demonstrate significant growth over long periods of time. Some studies have shown better survival for tumours $<1$ or $2 \mathrm{~cm}[72,73]$, but others have not [69]. Because of the aforementioned biases and the fact that the biological behaviour of very early detected lung cancer is yet unknown, only randomized clinical trials (RCTs) will enable the determination of whether lung cancer screening will reduce disease-specific mortality [74-77]. Intermediate end-points, such as 5-yr survival, resection rate and stage of disease at diagnosis (stage migration or shift), should be reported as part of an interim analysis, but cannot replace mortality as the only unbiased end-point. The assumption that a single-arm study would take less time than a properly conducted randomized trial, with an adequate sample size, is not correct because in a controlled design it is much easier to determine if a mortality difference has arisen early, as could happen if there is an important early effect of CT screening. However, it is also incorrect to conclude that there is no place for singlearm cohort studies, because these can answer several unresolved questions such as the interval and frequency of follow-up repeat CTs, the evaluation of new technologies, the management of ground-glass opacities, and the role of biomarkers [78]. Single-arm cohort studies and RCTs are complementary and should not be regarded as competitive.

\section{Management of early detected lung cancer}

The use of the spiral CT for lung cancer screening will result in an increased number of both diagnostic and therapeutic thoracic procedures involving very small lesions. The current World Health Organization (WHO) lung cancer staging system does not take into account lesions of this size; therefore, treatment should not solely be based on the current staging system. For a lesion deemed suspicious for malignancy by imaging criteria, the diagnostic procedure to confirm malignancy should be the least invasive procedure available. In the ELCAP study confirmation of malignant disease was obtained by CT-guided fine-needle aspiration (FNA) in $80 \%$ of the cases prior to surgery [44]. FNA with fluoroscopic or CT guidance is a well-established and safe method for diagnosing malignant and benign pulmonary nodules. The sensitivity and specificity of FNA in small pulmonary nodules of $\leqslant 15 \mathrm{~mm}$ has been reported at between $85 \%-93 \%$ and $100 \%$, respectively [79-81]. However, the dependence on cytological examination remains a limitation. A transthoracic core-needle biopsy (CNB) provides a tissue core for histological examination, which increases the chances of a specific diagnosis. In two large series, the sensitivity and specificity of an automated 20-gauge CT-guided CNB was $>90 \%$ and $>100 \%$, respectively, without difference between lesions $>20 \mathrm{~mm}$ and $<20 \mathrm{~mm}[82,83]$. The pneumothorax rate has been reported at $4-25 \%$ [82-84], but only a minority (3-5\%) required chest 
tube drainage [82-84]. Pathological diagnosis may lead to three broad categories of findings: inflammatory, atypical bronchoalveolar proliferation (atypical adenomatous hyperplasia (AAH) or bronchoalveolar carcinoma (BAC)) and invasive carcinoma. Inflammatory lesions should be followed radiologically without immediate intervention. AAH is a less specific category for which the initial intervention may be wedge resection, whereupon an attempt is made to evaluate the invasiveness [48]. An elastin stain on frozen tissue can aid in the assessment of the intactness of the basement membrane to differentiate noninvasive BAC (Noguchi Type A or B) from BAC with microinvasion (Noguchi Type $\mathrm{C}$ ) prior to the decision to perform a lobectomy or a more limited resection [85]. If invasion is found, standard lobectomy should be performed. Current standard care for small-sized lung cancers is lobectomy and mediastinal lymph node sampling or dissection. Limited resections in patients with stage I tumours lead to a higher recurrence rate $[86,87]$. Even in peripheral lung cancers of $<10 \mathrm{~mm}$, more than one-third appear to be invasive [88]. Therefore, wedge resections should be discouraged, except in pulmonary compromised individuals. If after wedge resection invasive cancer is found, completion lobectomy with lymph node sampling is the treatment of choice provided that the pulmonary reserve is adequate. If not, postoperative radiation therapy can be considered.

Radiotherapy can be curative in a significant proportion of patients with medically inoperable stage I nonsmall cell lung cancer. A cancer-specific survival of $42 \%$ and $31 \%$ at 3 and 5 yrs, respectively, has been reported after a dose of 60-65 Gy $[89,90]$. A review of 10 studies using two-dimensional treatment planning and a median dose of 60-66 Gy revealed a low incidence of serious complications and, thereby indicating that higher radiotherapy doses are feasible in stage I disease [90]. Ongoing radiation dose-escalation studies have now enabled the delivery of doses of up to $102 \mathrm{~Gy}$ for small target volumes [91, 92].

The optimal management of nonsolid opacities, so-called "ground-glass opacities" (GGO) is not yet established. A GGO is defined as a partially opaque region that does not obscure the structures contained within (e.g. vessels). So far, there is little data available concerning the frequency and natural history of these GGOs. Pathological review of resected GGOs resulted in the diagnosis of either inflammation (infectious), fibrosis (scar tissue), AAH, BAC or invasive carcinoma. Two subtypes can be identified: pure and mixed. A pure GGO is a focal translucency, which is homogeneous in appearance, without the presence of solid or linear components or distortion of lung parenchyma (e.g. convergence of vessels). A mixed GGO is a focal translucency, which has at least one of the following features: heterogeneous appearance, the presence of solid or linear components or distortion of the lung parenchyma (e.g. convergence of vessels). It is generally recognized that pure GGOs are indolent and that a relatively high percentage of these remain stable over periods of years; whereas, the malignancy rate of mixed GGOs may be as high for solid nodules, thus making their work-up and treatment the same [49]. For pure GGOs, management recommendations are not yet available, but most investigators favour a conservative approach with CT monitoring for growth of the lesion [49].

\section{The launching of a lung cancer screening trial}

Before launching a screening trial, most of the 10 different principles of screening should be met (table 3) [93]. In lung cancer screening, most of these criteria seem to be fulfilled. 1) Lung cancer is an important health problem, with relatively high incidence and mortality rates and a very high mortality/ incidence ratio. 2) There is universal agreement about the appropriate treatment for different stages of lung cancer, with surgery being the curative option for localized lesions. 3) Diagnostic methods and treatment possibilities are available without major negative effects. 4) Several pilot studies including $>20,000$ persons with CT have identified smaller lesions in earlier stages (than identified with CXR), shown to be malignant at histological examination. 5) The lowdose spiral CT is a modern possible screening tool with low radiation exposure. 6) It is as yet unknown whether CT is acceptable for the population as a whole, but this will be part of further research (quality of life (QOL) assessment). 7) The natural history of lung cancer is partially understood. Only in a randomized trial can one evaluate whether the detection and treatment of early lesions will change the natural course of the disease, prevent micrometastases occurring, and prevent disease-specific death. Nonrandomized studies will be unable to show this. 8) According to (inter)national guidelines, there is agreement whom to treat. 9) Given the high incidence and mortality, an effective programme may potentially have a large impact on health of the population at risk. If a

Table 3. - WILSON and JUNGNER [93] principles of screening

The condition sought should be an important health problem

There should be an accepted treatment for patients with recognized disease

Facilities for diagnosis and treatment should be available

There should be a recognizable latent or early symptomatic stage

There should be a suitable test or examination

The test should be acceptable to the population

The natural history of the condition, including development from latent to declared disease, should be adequately understood There should be an agreed policy on whom to treat as patients

The costs of case-finding (including diagnosis and treatment of patients diagnosed) should be economically balanced in

relation to possible expenditure on medical care as a whole

Case finding should be a continuing process and not a "once and for all" project 
reduction in lung cancer mortality is established the potential number of life-yrs gained will be significant. It is not yet known whether the benefits of lung cancer screening will outweigh the induced cost and potential harm to the population studied, but it is expected that the cost of case finding will be economically balanced as treatment of lung cancer in early stages is less expensive than later. The cost of the screening may not be much different from nationwide screening programmes that are presently running. However, this evaluation must be part of future screening trials. Lastly, 10) screening should be a continuing process with long-term follow-up.

\section{European initiatives for randomized and one-armed clinical trials}

The publication of the ELCAP study in 1999 [44] has generated a tremendous renewed interest in lung cancer screening. At the Third International Conference on Screening for Lung Cancer in New York, USA, October 2000, researchers from several European countries discussed the need for a coordination and collaboration of the European initiatives on lung cancer screening. It was decided to set up a European working group under the umbrella of the International Association for the Study of Lung Cancer (IASLC) European Group for Early Detection of Lung Cancer, in order to facilitate and strengthen European initiatives of lung cancer screening. European researchers participating in the meeting in New York agreed that there is a great need for evaluation of low dose CT screening in properly conducted RCTs. So far, protocols for RCTs have been prepared by Denmark, France, Germany, the Netherlands, Italy, Norway and the UK, as summarized in table 4 . The protocols, prepared in different European countries, represent the work of independent groups of doctors in each country, and are based on extensive discussions among these experts. Therefore, each protocol may be regarded as a presentation of what is judged the best procedure in each country. All the protocols have many similarities, but there are some differences. All the protocols use an "ELCAPlike" evaluation of suspicious findings at CT, and all RCTs have mortality as a primary end-point. The protocols from Denmark, the Netherlands, Norway, Italy and the UK are quite similar in design, and compare CT screening with no screening in the control group. The French protocol includes a prerandomization CT screening of 27,000 participants. Only participants without any nodules visible on CT $(20,000)$ will be randomized between the screen and control arm. In addition, a final CT scan is performed in the control group at the end of the 5-yr trial period. In the German trial, CXR screening will be performed in the control arm. In most countries, recruitment will be achieved by media campaigns, but in Denmark and the Netherlands a random population sample will be taken by sending a personal invitation to all subjects of the target population. Applications for funding have been submitted in each country.

Several one-armed cohort studies are running, or have recently been initiated, in the following European countries: Germany (Muenster, S. Diederich; Munich, U.J. Schoepf), Israel (Jerusalem, D. Shaham; Tel Aviv, D. Krupsky), Italy (Rome, S. Giunta; Milan, U. Pastorino), Spain (Pamplona, J. Zulueta) and Switzerland (Zurich, K. Klingler). They all follow the ELCAP design for follow-up of CT detected nodules.

Table 4. - Planned European randomized trials for lung cancer screening with low dose spiral computed tomography

\begin{tabular}{|c|c|c|c|c|c|c|c|}
\hline & Denmark & France & Germany & Holland & Italy & Norway & UK \\
\hline \multicolumn{8}{|l|}{ Inclusion criteria } \\
\hline Age yrs & $50-65$ & $50-74$ & $55-69$ & $50-74$ & $55-69$ & $60-69$ & $60-74$ \\
\hline Current smokers pack-yrs & $>20$ & $>15$ & $>40$ & $>20$ & $>10$ & $>20$ & $>20$ \\
\hline Exsmokers pack-yrs & No & Yes & $<5$ yrs & $<5$ yrs & $<5$ yrs & $<5$ yrs & No \\
\hline History of cancer allowed & No & No & No & No & No & $?$ & $?$ \\
\hline \multicolumn{8}{|l|}{ Protocol design } \\
\hline Total number & 10000 & 20000 & 40000 & 24000 & 10000 & 24000 & 40000 \\
\hline Randomization & $1: 1$ & $1: 1$ & $1: 1$ & $1: 2$ & $1: 1$ & $1: 1$ & $1: 1$ \\
\hline Multicentre & No & Yes & Yes & No & Yes & Yes & Yes \\
\hline Screening period yrs & 6 & 5 & 5 & 3 & 4 & 5 & 5 \\
\hline Screening frequency & Annual & Annual & Annual & Annual & Annual & Annual & Annual \\
\hline Follow-up yrs & 5 & 3 & 10 & 7 & 3 & Yes & $3-5$ \\
\hline Screening in control group & No & No & CXR & No & No & No & No \\
\hline Final screen in control group & No & CT & CXR & No & No & No & No \\
\hline Smoking cessation & Yes & Yes & Yes & No & Yes & Yes & Yes \\
\hline Diagnostic work-up & ELCAP & ELCAP & ELCAP & ELCAP & ELCAP & ELCAP & ELCAP \\
\hline $\begin{array}{l}\text { Verification of } \\
\text { cause of death }\end{array}$ & $\begin{array}{c}\text { Central } \\
\text { death register }\end{array}$ & $\begin{array}{l}\text { Central } \\
\text { review }\end{array}$ & $\begin{array}{l}\text { Follow } \\
\text { up }\end{array}$ & $\begin{array}{c}\text { Central } \\
\text { death register }\end{array}$ & $\begin{array}{l}\text { Local death } \\
\text { register }\end{array}$ & $\begin{array}{c}\text { Central } \\
\text { death register }\end{array}$ & $\begin{array}{l}\text { Central death } \\
\text { register }\end{array}$ \\
\hline \multicolumn{8}{|c|}{ се } \\
\hline Mortality & Yes & Yes & Yes & Yes & Yes & Yes & Yes \\
\hline Health economics & Yes & Yes & $?$ & Yes & No & $?$ & Yes \\
\hline Quality of life & Yes & Yes & $?$ & Yes & Yes & $?$ & Yes \\
\hline
\end{tabular}

CXR: Chest radiograph; CT: computed tomography; ELCAP: Early Lung Cancer Action Project [44, 58]. 


\section{Conclusion}

The advent of low-dose spiral computed tomography scanning has made it possible to detect early invasive lung cancer in a screening context. The technique has been introduced in Japan and USA, but only sparsely in Europe. The initial results are so promising that it can be anticipated that a great demand for the testing of smokers and exsmokers will arise in the future. It is therefore very important that low-dose computed tomography screening is evaluated in randomized trials as soon as possible in order to permit evidence based conclusions on the value of this technique. The potential benefit is enormous if computed tomography screening truly reduces mortality and extends survival from this disease. However, it is also important to take into consideration the potential hazards and harms incurred by a screening process in the population. The impact and magnitude of such a screening process is also best clarified in a randomized trial. The planned European studies should, therefore, be initiated as soon as possible and may also be of great value to the international community.

\begin{abstract}
Acknowledgements. The authors would like to thank S. Sone, Shinshu University, Matsumoto, Nagano, Japan for providing us with the data on spiral computed tomography screening programmes in Japan. R.J. van Klaveren was associated with this review on behalf of the Rotterdam Oncologic Thoracic Study Group (ROTS).
\end{abstract}

\section{References}

1. Landis SH, Murray T, Bolden S, Wingo PA. Cancer statistics 1999. CA Cancer J Clin 1999; 49: 4446.

2. Mountain CF. Revisions in the international system for staging lung cancer. Chest 1997; 111: 1710-1717.

3. Feinstein AR, Sosin DM, Wells CK. The Will Rogers phenomenon. Stage migration and new diagnostic techniques as a source of misleading statistics for survival of cancer. NEJM 1985; 312: 1604-1608.

4. Rodu B, Cole P. The fifty-year decline of cancer in America. J Clin Oncol 2001; 19: 239-241.

5. Richards MA, Stockton D, Babb P, Coleman MP. How many deaths have been avoided through improvements in cancer survival? BMJ 2000; 320: 895-898.

6. Smith RA, Mettlin CJ, Davis KJ, Eyre H. American Cancer Society guidelines for the early detection of cancer. CA Cancer J Clin 2000; 50: 3449.

7. Lancaster T, Stead L, Silagy C, Sowden A. Effectiveness of interventions to help people stop smoking: findings from the Cochrane Library. BMJ 2000; 321: 355-358.

8. Weiss W, Boucot KR, Cooper DA. The Philadelphia Pulmonary Neoplasm Research Project: early roentgenographic appearance of bronchogenic carcinoma. Arch Intern Med 1974; 134: 306-311.

9. Lilienfeld A, Archer PG, Burnett CH. An evaluation of radiologic and cytologic screening for the early detection of lung cancer: a cooperative pilot study of the American Cancer Society and the Veterans Administration. Cancer Res 1966; 2: 2083-2121.

10. Hayata Y, Funatsu H, Kato H. Results of lung cancer screening programs in Japan: early detection and localization of lung tumors in high risk groups. In: Band PR, ed. Recent Results of Cancer Research. Vol 82. Heidelberg, Springer Berlin, 1982; pp. 179-186.

11. Nash FA, Morgan JM, Tomkins JG. South London Lung Cancer Study. BMJ 1968; 2: 715-721.

12. Brett GZ. Earlier diagnosis and survival in lung cancer. $B M J$ 1969; 4: 260-262.

13. Wilde J. A 10-year follow-up of semiannual screening for early detection of lung cancer in the Erfurt country, GDR. Eur Respir J 1989; 2: 656-662.

14. Berlin NI, Buncher CR, Fontana RS, Frost JK, Melamed MR. The National Cancer Institute Cooperative Early Lung Cancer Detection Program. Results of the initial screen (prevalence). Am Rev Respir Dis 1984; 130: 545-549.

15. Flehinger BJ, Melamed MR, Zaman MB, Heelan RT, Perchick WB, Martini N. Early lung cancer detection: results of the initial (prevalence) radiologic and cytologic screening in the Memorial Sloan-Kettering Study. Am Rev Respir Dis 1984; 130: 555-560.

16. Frost JK, Ball WC, Levin ML, et al. Early lung cancer detection: results of the initial (prevalence) radiologic and cytologic screening in the John Hopkins Study. Am Rev Respir Dis 1984; 130: 549-554.

17. Fontana RS, Sanderson DR, Taylor WF, et al. Early Lung cancer detection: results of the initial (prevalence) radiologic and cytologic screening in the Mayo Clinic study. Am Rev Respir Dis 1984; 130 : 561-570.

18. Melamed MR, Flehinger BJ, Zaman MB. Screening for early cancer: results of the Memorial SloanKettering study in New York. Chest 1984; 86: 4449.

19. Fontana RS, Sanderson DR, Woolner LB. Lung cancer screening: the Mayo Program. J Occup Med 1986; 28: 746-750.

20. Kubik A, Polak J. Lung cancer detection. Results of a randomized prospective study in Czechoslovakia. Cancer 1986; 57: 2427-2437.

21. American Cancer Society. Report on the cancerrelated health check-up: cancer of the lung. $C A$ Cancer J Clin 1980; 30: 199-207.

22. Thompson S, Bucknall C, Pearson MMG. Presenting symptoms and signs of lung cancer - Significance and relation to tumor type. Am J Respir Crit Care Med 1999; 159: A61.

23. Van Meerbeeck JP, Meurs CJC, Damhuis RAM and on behalf of the Rotterdam Oncology Study Group and the Regional Tumour Working Parties. Patterns of care for non-small cell lung cancer patients in the Netherlands: an analysis of cancer registry data. Proceedings ERS Madrid, Spain, Jan 1999, A2924.

24. Fontana RS, Sanderson DR, Woolner LB. Screening for lung cancer: a critique of the Mayo Lung Project. Cancer 1991; 67: 1155-1164.

25. Wolpaw DR. Early detection in lung cancer. Case finding and screening. Med Clin North Am 1996; 80: 63-82.

26. Strauss GM, Gleason RE, Sugarbaker DJ. Chest $\mathrm{X}$-ray screening improves outcome in lung cancer. A reappraisal of randomised trials on lung cancer screening. Chest 1995; 107: 270s-279s.

27. Strauss GM, Gleason RE, Sugarbaker DJ. Screening 
for lung cancer: another look, a different view. Chest 1997; 111: 754-768.

28. Davis MP. There and back again. Lung cancer screening. Chest 1997; 111: 532-534.

29. Kennedy TC, Miller Y, Prindiville S. Screening for lung cancer revisited and the role of sputum cytology and fluorescence bronchoscopy in a high-risk group. Chest 2000; 117: 72s-79s.

30. Marcus PM, Bergstralh EJ, Fagerstrom RM, Williams DE, Fontana R, Taylor WF. Lung cancer mortality in the Mayo Lung Project: impact of extended follow-up. J Natl Cancer Inst 2000; 92: 1308-1316.

31. Smith IE. Screening for lung cancer: time to think positive. Lancet 1999; 354: 86-87.

32. Soda H, Tomita H, Kohno S, Oka M. Limitation of annual screening chest radiography for the diagnosis of lung cancer. A retrospective study. Cancer 1993; 72: 2341-2346.

33. Soda H, Oka M, Tomita H, Nagashima S, Soda M, Kohno S. Length and lead time biases in radiologic screening for lung cancer. Respiration 1998; 28: 511517.

34. Quenkel GBA, Kessels AGH, Goei R, van Engelshoven JMA. Miss rate of lung cancer on the chest radiography in clinical practice. Chest 1999; 115: 720-724.

35. Sone S, Li F, Yang ZG, et al. Characteristics of small lung cancers invisible on conventional chest radiography and detected by population based screening using spiral CT. Br J Radiology 2000; 73: 137-145.

36. Gohagan JK, Prorok PC, Kramer BS, Cornett JE. Prostate cancer screening in the prostate, lung colorectal and ovarian cancer screening trial of the national cancer institute. J Urology 1994; 154: 1905 1909.

37. Prorok PC, Andriole GL, Bresalier RS, et al. Design of the Prostate, Lung, Colorectal and Ovarian (PLCO) Cancer Screening Trial. Control Clin Trials 2000; 21: 273s-309s.

38. Gohagan JK, Prorok PC, Hayes RB, Kramer BS. The Prostate, Lung, Colorectal and Ovarian (PLCO) Cancer Screening Trial of the National Cancer Institute: history, organization and status. Control Clin Trials 2000; 21: 251s-272s.

39. Henschke CI, Miettinen OS, Yankelevitz DF, Libby DM, Smith JP. Radiographic screening for cancer. Proposed paradigm for requisite research. Clin Imag 1994; 18: 16-20.

40. Kaneko M, Eguchi K, Ohmatsu H, et al. Peripheral lung cancer: screening and detection with low-dose spiral CT versus radiography. Radiology 1996; 201: 798-802.

41. Mori K, Tominaga K, Hirose T, Sasagawa M, Yokoyama K, Moriyama N. Utility of low-dose helical CT as a second step after plain chest radiography for mass screening for lung cancer. $J$ Thorac Imag 1997; 12: 173-180.

42. Itoh S, Ikedam M, Isomura $\mathrm{T}$, et al. Screening helical CT for mass screening of lung cancer: Application of low-dose and single-breath-hold scanning. Rad Med 1998; 16: 75-83.

43. Sone S, Takashima S, Li F, et al. Mass screening for lung cancer with mobile spiral computed tomography scanner. Lancet 1998; 351: 1242-1245.

44. Henschke CI, McCauley DI, Yankelevitz DF, et al. Early lung cancer action project: overall design and findings from baseline screening. Lancet 1999; 354: 99 105.
45. Swenson SJ. Lung cancer screening: low-dose CT. Presented at the Society of Thoracic Radiology Meeting, San Diego, CA, USA, March 12-16, 2000.

46. Diederich S, Lenzen H. Radiation exposure associated with imaging of the chest: comparison of different radiographic and computed tomography techniques. Cancer 2000; 89: 2457-2460.

47. Oguchi K, Sone S, Kiyono K, Takashima S, Maruyama Y, Hasegawa H. Optimal tube current for lung cancer screening with low-dose spiral CT. Acta Radiol 2000; 41: 532-536.

48. Chamberlain J, Clifford RE, Nathan BE, Price JL, Burns I. Repeated screening for breast cancer. J Epidemiol Community Health 1984; 38: 54-57.

49. Proceedings of the 4th International Conference on screening for lung cancer. Cornell University, New York, USA, February 23-25, 2001.

50. Day NE. Estimating the sensitivity of a screening test. J Epidemiol Community Health 1985; 39: 364-366.

51. Paci E, Duffy SW. Modelling the analysis of breast cancer screening programmes: sensitivity, lead time and predictive value in the Florence District Programme (1975-1986). Int J Epidemiol 1991; 20: 852858.

52. Midthun DE, Swensen SJ, Jett JR, et al. Screening for lung cancer with low-dose spiral computed tomography. Lung Cancer 2000; 29: Suppl. 1, 241.

53. Sone S, Li F, Yang Z-G, et al. Results of three-year mass screening programme for lung cancer using mobile low-dose spiral computed tomography scanner. Br J Cancer 2001; 84: 25-32.

54. Kakinuma R, Ohmatsu H, Kaneko M, et al. Detection failures in spiral CT screening for lung cancer: analysis of CT findings. Radiology 1999; 212: 61-66.

55. Tossavainen A. International expert meeting on new advances in the radiology and screening of asbestosrelated diseases. Consensus report. Scand J Work Environ Health 2000; 26: 449-454.

56. Diederich S, Lenzen H, Wormanns D, et al. Screening for asymptomatic bronchogenic carcinoma with lowdose spiral-CT of the chest: findings in 816 smokers. Proceedings ECR, Vienna, Austria, March 7-12, 1999, s153.

57. Nishiyama H, Kaneko M, Ohmatsu H. Usefulness of spiral CT scan for early detection of lung cancer our experience at the Anti-Lung Cancer Association (ALCA). Lung Cancer 2000; 29: Suppl. 1, 249.

58. Aberle D, Gamsu G, Henschke CI, Naidich DP, Swensen SJ. A consensus statement of the society of thoracic radiology. Screening for lung cancer with helical computed tomography. J Thorac Imaging 2001; 16: 65-68.

59. Yankelevitz DF, Gupta R, Zhao B, Henschke CI. Small pulmonary nodules: evaluation with repeat CTpreliminary experience. Radiology 1999; 212: 561-566.

60. Yankelevitz DF, Reeves AP, Kostis WJ, Zhao B, Henschke CI. Small pulmonary nodules: volumetrically determined growth rates based on CT evaluation. Radiology 2000; 217: 251-256.

61. Soda H, Oka M, Tomita H, Nagashima S, Soda M, Kohno S. Length and lead time biases in radiologic screening for lung cancer. Respiration 1999; 66: 511517.

62. Black WC. Overdiagnosis: An underrecognized cause of confusion and harm in cancer screening. J Natl Cancer Inst 2000; 92: 1280-1282.

63. Mc Farlane MJ, Feinstein AR, Wells CK. Necropsy 
evidence of detection bias in the diagnosis of cancer. Arch Int Med 1986; 146: 1695-1698

64. Mc Farlane MJ, Feinstein AR, Wells CK. Clinical features of lung cancers detected as a postmortem surprise. Chest 1986; 90: 520-523.

65. Sobue T, Suzuki T, Matsuda M. Survival for clinical stage I lung cancer not surgically treated. Cancer 1992; 69: 685-692.

66. Flehinger BJ, Kimmel M, Melamed MR. The effect of surgical treatment on survival from early lung cancer: implications for screening. Chest 1993; 101: 10131018.

67. Mc Farlane MJ, Feinstein AR, Wells CK. The epidemiologic necropsy. JAMA 1987; 258: 331-338.

68. Walter SD, Kubic A, Parkin DM, Ressigova J, Adamec M, Khlat M. The natural history of lung cancer estimated from the results of a randomized trial of screening. Cancer Causes Control 1992; 3: 115-123.

69. Sobue T, Nakayama T. Re: Lung cancer mortality in the Mayo Lung Project: Impact of extended followup. J Natl Cancer Inst 2001; 93: 320-321.

70. Patz EF, Rossi S, Harpole DH, Weaver AL, Midthun DE. Correlation of tumor size and survival in patients with stage IA non-small cell lung cancer. Chest 2000; 117: $1568-1571$.

71. Takigawa N, Segawa Y, Nakata M, et al. Clinical investigation of atypical adenomatous hyperplasia of the lung. Lung Cancer 1999; 25: 115-121.

72. Martini N, Bains MS, Burt ME, et al. Incidence of local recurrence and second primary tumors in resected stage I lung cancer. J Thorac Cardiovasc Surg 1995; 109: 120-129.

73. Suzuki K, Nagai K, Yoshida K, et al. Conventional clinicopathologic prognostic factors in surgically resected nonsmall cell lung carcinoma. Cancer 1999; 86: 1976-1984.

74. Patz EF, Goodman PC, Bepler G. Screening for lung cancer. Review Article. NEJM 2000; 343: 1627-1633.

75. Newman L. Larger debate underlies spiral CT screening for lung cancer. $J$ Natl Cancer Inst 2000; 92: 592594.

76. Smith IE. Screening for lung cancer: time to think positive. Lancet 1999; 354: 86.

77. Smith RA, Glynn TJ. Early lung cancer detection. Current and ongoing challenges. Cancer 2000; 89: 2327-2328.

78. Mulshine JL, Henschke CI. Prospects for lung cancer screening. Lancet 2000; 355: 592-593.

79. Westcott JL, Rao N, Colley DP. Transthoracic needle biopsy of small pulmonary nodules. Radiology 1997; 202: 97-103.

80. Tomiyama N, Mihara N, Maeda M, et al. CT-guided needle biopsy of small pulmonarty nodules: value of respiratory gating. Radiology 2000; 217: 907-910.

81. Haga Y, Fujisawa T, Baba M, et al. Percutaneous fine needle aspiration cytology with CT fluoroscopy can increase diagnostic rates in patients with small sized pulmonary nodules undiagnosed by bronchoscopy. Lung Cancer 2000; 29: Suppl. 1, 247.

82. Laurent F, Latrabe V, Vergier B, Montaudon M, Vernejoux J-M, Dubrez J. CT-guided transthoracic needle biopsy of pulmonary nodules smaller than $20 \mathrm{~mm}$ : results with an automated 20 -gauge coaxial cutting needle. Clin Radiol 2000; 55: 281-287.

83. Charig MJ, Philips AJ. CT-guided cutting needle biopsy of lung lesions - Safety and efficacy of an outpatient service. Clin Radiol 2000; 55: 964-969.

84. Hänninen EL, Vogl TJ, Ricke J, Felix R. CT-guided percutaneous core biopsies of pulmonary lesions. Acta Radiol 2001; 42: 151-155.

85. Noguchi M, Morikawa A, Kawasaki M, et al. Small adenocarcinoma of the lung. Histologic characterisation and prognosis. Cancer 1995; 75: 2844-2852.

86. Ginsberg RJ, Rubinstein LV. Randomized trial of lobectomy versus limited resection for T1NO nonsmall cell lung cancer: Lung Cancer Study Group. Ann Thorac Surg 1995; 60: 6615-6623.

87. Iichinose Y, Yano T, Yokoyama H. The correlation between tumor size and lymphatic vessel invasion in resected peripheral stage I non-small cell lung cancer. J Thorac Cardiovasc Surg 1994; 108: 684-686.

88. Yoshida J, Nagai K, Yokose T, et al. Primary peripheral lung carcinoma smaller than $1 \mathrm{~cm}$ in diameter. Chest 1998; 114: 710-712.

89. Sibley GS, Jamieson TA, Marks LB, Anscher MS, Prosnitz LR. Radiotherapy alone for medically inoperable stage I non-small-cell lung cancer: the Duke experience. Int J Radiat Oncol Biol Phys 1998; 40: 149_ 154.

90. Sibley GS. Radiotherapy for patients with medically inoperable Stage I non-small cell lung carcinoma: smaller volumes and higher doses - a review. Cancer 1998; 82: 433-438.

91. Hayman JA, Martel MK, Ten Haken RK. Dose escalation in non-small cell lung cancer using conformal 3-dimensional radiation therapy: Update of a phase I trial. J Clin Oncol 1999; 18: 459a.

92. Robertson JM, Ten Haken RK, Hazuka MB, et al. Dose escalation for non-small cell lung cancer using conformal radiation therapy. Int $J$ Radiat Oncol Biol Phys 1997; 37: 1079-1085.

93. Wilson JMP, Jungner G. Principles and Practice of Screening for Disease. Geneva, Switzerland, World Health Organization, 1968. Public Health Papers, number 39 . 